\title{
Outcomes of Incidental Findings on Multi-Detector Computed Tomography for Transcatheter Aortic Valve Implantation Assessment: A Single-Centre Study and Review of the Literature
}

Francis J. Ha MBBS BMedSci ${ }^{1}$, Jodie Li Mei Tham ${ }^{1,2}$ MD, Sarang Paleri MD ${ }^{1}$, Christine Wright RN $^{1}$, Kelvin K Yap MBBS MMed FRACP FRANZCR ${ }^{3}$,

Heath SL Adams MBBS, BMed Sci, FRACP ${ }^{1,4}$, Robert J Whitbourn BSci, MBBS, FRACP ${ }^{1,2}$, Sonny C Palmer BA, BSc, MBBS DMedSci FRACP ${ }^{1,2}$

1. Department of Cardiology, St Vincent's Hospital Melbourne

2. Department of Medicine, University of Melbourne

3. Medical Imaging Department, St Vincent's Hospital Melbourne

4. Faculty of Health Science, University of Tasmania

Corresponding Author: Dr Sonny Palmer

Email: sonny.palmer@svha.org.au

St Vincent's Hospital Melbourne

41 Victoria Parade, Fitzroy, Victoria, 3065

Telephone: +610392313000

Word count: 2995

Conflicts of interest: the authors report no relevant conflicts of interest

Running title: MDCT for TAVI workup: Incidental findings

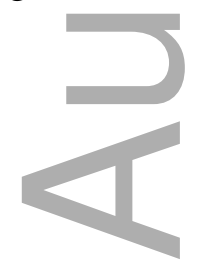

This is the author manuscript accepted for publication and has undergone full peer review but has not been through the copyediting, typesetting, pagination and proofreading process, which may lead to differences between this version and the Version of Record. Please cite this article as doi: $\underline{10.1111 / 1754-9485.12872}$

This article is protected by copyright. All rights reserved 
3

4

5

6

7

8

Article type : Radiology Original Article
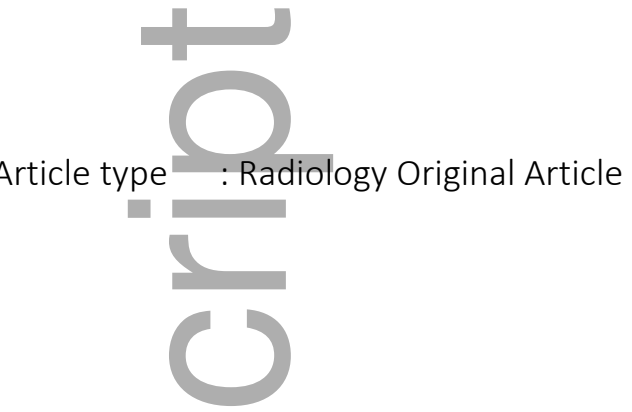

\section{ABSTRACT}

\section{Introduction}

Patients with severe aortic stenosis (AS) require multi-detector computed tomography (MDCT) when considered for transcatheter aortic valve implantation (TAVI). Incidental findings on MDCT are common given the age group and region imaged. Our aim was to evaluate the frequency and outcome of incidental findings (IF) identified on MDCT and the impact on survival.

\section{Methods}

This single-centre analysis retrospectively reviewed severe AS patients who underwent MDCT during TAVI workup. MDCT reports were reviewed for any IF and defined into three categories: IF of no relevant clinical significance (IF-NoCS), IF of non-immediate clinical significance (IF-NICS) and IF of immediate clinical significance (IF-ICS). Demographics, follow-up of IF, and survival was calculated from MDCT date.

\section{Results}

265 patients underwent MDCT for TAVI suitability (mean age 83 \pm 6 years, 52\% male). The majority proceeded to TAVI (65\%). Renal lesions (25\%) and lung nodules (18\%) were the most common IF. Fifty-nine patients (22\%) had IF-NICS; 39\% (23/59) were benign, 59\% were not further investigated and one patient had suspected lung cancer. Six patients $(2.3 \%)$ had IFICS and all were diagnosed with lung cancer. During a median follow-up of 272 days, there was 
no survival difference between patients with IF-ICS or IF-NICS versus patients without IF or IF-

2 NoCS overall $(\mathrm{p}=0.44)$ or in TAVI patients TAVI $(\mathrm{p}=0.88)$.

3

\section{Conclusion}

IF on MDCT are common with one-quarter having IF-ICS or IF-NCIS. Most patients with IF-NICS did not undergo further investigation. Standardised reporting of MDCT may assist in clarifying the need for further investigation which will in turn influence decision and timing to proceed with TAVI.

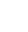

\section{Abstract word count: 250}

\section{INTRODUCTION}

Transcatheter aortic valve implantation (TAVI) for severe aortic stenosis (AS) is increasingly performed in Australia(1). Current guidelines recommend Heart Team assessment and TAVI in patients with severe symptomatic AS who are inoperable or high risk for surgery(2). In the assessment of suitability for TAVI, patients undergo focused cardiac investigations including a TAVI protocol contrast multi-detector computed tomography (MDCT). The scan extends from the mandible to the femoral head and is required for identification and accurate sizing of the annulus, the assessment of calcification burden particularly within the left ventricular outflow tract, assessment of the potential risk of coronary occlusion and in order to determine the most appropriate vascular access route(3). As severe AS patients are often elderly and due to the number of non-cardiac organs captured in MDCT, incidental findings (IF) are common and are reported in up to $70 \%$ of cases(4).

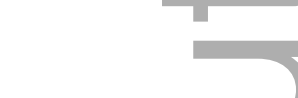

The significance of IF found on MDCT is currently unclear. The definition of IF ranges between studies from simple colorectal diverticulosis or hernias to potentially malignant cancers(5). Such findings may reduce the likelihood of receiving TAVI and delay time from MDCT to the TAVI procedure(5). Previous studies have focused on the impact of MDCT-IF on survival, yielding conflicting results(4-9). Differences likely reflect variations in the definition of IF, the threshold of reporting findings, and malignant potential of individual findings. So far, there are limited 
data assessing the follow-up of IF in patients with severe AS. Moreover, it is unclear how many patients have MDCT findings correlated with previous imaging, undergo further diagnostic imaging, and how many suspicious findings are discovered to be malignant. This study reviewed consecutive cases of patients with severe AS from a tertiary centre who underwent MDCT in the workup for TAVI to identify the types of IF, the outcome of IF on patient follow-up, and the influence of IF on survival.

\section{METHODS}

We reviewed consecutive patients from a prospectively-maintained registry who underwent MDCT as part of TAVI workup at a tertiary institution over 10 years (2009 to 2018). The registry included all patients who had been referred for TAVI consideration and thus also included patients who did not proceed to TAVI. Retrospective electrocardiogram-gated cardiac and delayed Flash angiographic phases were performed for image acquisition using one of three available systems (GE Revolution CT 256-slice scanner; GE Healthcare, Chicago, United States; Siemens Somatom Sensation 64 and Siemens Definition Flash 128-slice scanner; Siemens AG, Germany). The MDCT was assessed by a consultant radiologist with varying degrees of experience and subspecialty exposure. There was no standardised template or protocol used for reporting MDCT for TAVI workup at our centre. The patient's technical suitability for TAVI was performed with the aid of the 3Mensio Structural Heart ${ }^{\mathrm{TM}}$ system (Pie Medical Imaging, Masstricht, Netherlands). This study was approved by the institution's ethics review committee.

Baseline demographic data included age (from MDCT date), gender, New York Heart Association (NYHA) class, relevant comorbidities, previous percutaneous coronary intervention (PCI) or coronary artery bypass grafting $(\mathrm{CABG})$, and previously diagnosed malignancy. Chronic kidney disease was defined as an estimated glomerular filtration rate less than or equal to $60 \mathrm{~mL} / \mathrm{min} / 1.73 \mathrm{~m}^{2}$. Further collected data included the date of MDCT, date of TAVI procedure

(if performed), date of last follow-up, and patient survival. 
Regarding IF on MDCT, reported pathologies across any internal organ were recorded and considered an IF. For lung, liver, kidney and pancreatic abnormalities (cyst or nodule or lesion), we also collected data on largest diameter where specified. Incidental findings were defined into three categories: IF with no relevant clinical significance (IF-NoCS) where the MDCT report did not suggest further investigation; IF with non-immediate clinical significance (IF-NICS) where the MDCT report suggested that it may warrant further investigation (correlation with previous imaging, further imaging or long term follow-up); and IF with immediate clinical significance (IF-ICS), where it required immediate investigation and was verbally communicated to the treating team. In patients with an IF-NICS and IF-ICS, we reviewed patient medical records to determine if any previous imaging was subsequently used for correlation, if patients underwent further investigation with an alternative imaging modality, or if patients underwent a follow-up scan to assess malignancy. For patients diagnosed with a malignant cancer from further investigation, we reviewed their subsequent follow-up and services involved in ongoing patient care.

\section{Statistical analyses}

Continuous data are presented as median with interquartile range (IQR) or if not normally distributed when visualised on histogram plot, presented as mean with standard deviation (SD). Between-group comparisons were performed using chi-square test for categorical variables and t-test or analysis of variance for continuous data. We characterised overall survival (death from any cause) from MDCT date using Kaplan-Meier method with log-rank test used for betweengroup comparisons. A p-value less than 0.05 was considered statistically significant. Statistical analyses were performed using STATA MP 14.0 (Stata Corp LP, College Station, TX).

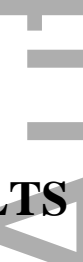

RESULTS

\section{Baseline characteristics}

27 Between 2009 and 2018, 265 patients with severe AS were identified with MDCT for assessment of TAVI suitability. In this cohort, 171 patients (65\%) underwent TAVI. Reasons for not 
proceeding with TAVI are detailed in Table S1 (Data Supplement). The most common reasons

2 for not proceeding included surgical aortic valve replacement candidate as per Heart Team assessment (37/94), frailty (28/94), unsuitable anatomy (11/94) and declining the procedure (10/94). The mean age in the entire cohort was $83 \pm 6$ years and most patients were NYHA class II $(62 \%)$ or III (25\%). Cardiovascular comorbidities included diabetes mellitus (32\%), hypercholesterolemia (66\%) and ischaemic heart disease (IHD; 49\%). About one-fifth of patients had undergone previous PCI $(21 \%)$ or previous CABG $(21 \%)$. Patients who did not proceed with TAVI were those with more frequent diabetes mellitus $(\mathrm{p}=0.04)$, but more absence of IHD ( $\mathrm{p}<0.001)$ and correspondingly less likely to have had previous PCI $(\mathrm{p}=0.03)$. Baseline characteristics are shown in Table 1.

\section{Incidental findings on MDCT}

Any IF was reported in 191 patients (72\%). The most common IF reported in MDCT included renal lesions $(67 / 265 ; 25 \%)$, lung nodules $(48 / 265 ; 18 \%)$ and colonic diverticulosis $(49 / 265$;

Incidental findings with non-immediate clinical significance

This article is protected by copyright. All rights reserved 
1 Fifty-nine patients (22\%) had IF-NICS (Figure 1). Amongst these patients, lung nodules were the most common pathology $(20 / 59 ; 34 \%)$ followed by renal pathology $(17 \%)$ and adrenal pathology (15\%). Twenty-three patients $(23 / 59 ; 39 \%)$ who underwent further investigation were demonstrated to have benign pathology. A suspicious lung malignancy was identified in one patient (patient no 1, Table 3) with IF-NICS. Due to extensive comorbidities, he was managed conservatively regarding possible lung cancer with 6-monthly CT and respiratory team follow-up. Upon discussion with the Heart Team, he underwent TAVI in the interim in view of the likely symptomatic benefit and reasonable life expectancy (>12 months). Most patients with IF-NICS did not undergo further investigation (59\%). Forty-four (75\%) patients with IF-NICS proceeded with TAVI

\section{Incidental findings with immediate clinical significance}

Six patients $(2.3 \%)$ were identified to have IF-ICS verbally communicated to the treating team (Figure 1 and Table 3). Five patients were found to have a primary lung malignancy following further investigation and referred to the respiratory team for multidisciplinary follow-up. One patient was found to have lung metastases on MDCT on a background of previous known colorectal malignancy which had been untreated (patient no. 4). After discussion with the Heart Team, one patient (patient no. 6) proceeded with TAVI prior to commencing oncology treatment in view of the likely symptomatic benefit and reasonable life expectancy for early-stage lung cancer (time from MDCT to TAVI, 97 days). A further patient underwent oncology treatment for lung cancer and after a stable remission was achieved, underwent TAVI about 1.65 years after his initial MDCT (patient no. 7). Figure 2 depicts the lung malignancy initially identified on MDCT in this patient. In four patients who did not undergo TAVI, three died from cancer-related complications. There were no differences in baseline characteristics between patients with either IF-NICS or IF-ICS compared with no IF or IF-NoCS (Table S2, Data Supplement).

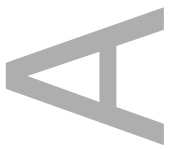

\section{Survival from MDCT}

There was no difference in time from date of MDCT to TAVI procedure between patients with IF-NICS compared with patients without IF or IF-NoCS (median 93 days [IQR 43-161 days] 
versus 85 days [43-147 days]; $\mathrm{p}=0.10)$. During a median follow-up of 272 days

2 (IQR, 131-632 days), there was no difference in overall survival from MDCT date between patients with IF-ICS or IF-NICS versus patients without IF or IF-NoCS in the overall cohort $(\mathrm{p}=0.44)$ or in patients who received TAVI $(\mathrm{p}=0.88$; Figure 3$)$.

\section{DISCUSSION}

The aim of this study was to evaluate the frequency and outcome of IF reported from MDCT as part of TAVI assessment. The main findings can be summarised as follows.
(1) A total of $22 \%$ of patients had IF-NICS and 6 patients (2.3\%) had IF-ICS

(2) The most common pathologies reported were renal lesions (25\%) and lung nodules (18\%)

(3) In six patients with IF-ICS, all were discovered to have a lung-related malignancy

(4) $59 \%$ of patients did not undergo further investigation for IF-NICS

(5) There was no difference in survival in patients with IF-NICS or IF-ICS compared with no IF or IF-NoCS in this cohort.

Incidental findings on MDCT for TAVI workup are common. As the field imaged extends from the mandible to the femoral heads, the scan has one of the highest rates of incidental noncardiovascular findings, especially due to the elderly age demographic (10). The incidence of IF ranges from $20 \%$ to $100 \%$ due to different definitions of an IF and varying thresholds for reporting by individual radiologists $(6,11-14)$. Renal and lung pathologies were the most commonly reported findings in our study and this is consistent with previous data(9). Of note, no dimensions or size were reported for most kidney nodules or cysts identified (69\%) and similarly for $29 \%$ of lung lesions. While reporting dimensions are presumably omitted due to either relatively small or benign nature of the pathology, this nevertheless has important implications for non-radiological clinicians who may be uncertain of the clinical significance of such findings. Our institution does not currently use a pre-specified template for reporting non-cardiac findings on MDCT in TAVI assessment. This likely influences the frequency of reported IF, and may 
reduce heterogeneity of reporting between radiologists, as has been demonstrated on other imaging techniques (15).

The impact that suspicious IF on MDCT have on overall survival remains unclear with several studies showing conflicting results (Table 4). In a single-center retrospective analysis of 553 patients who underwent TAVI with a follow-up of 5 years, a potentially malignant IF independently predicted all-cause mortality (adjusted HR 1.46, 95\% CI 1.07-1.99) (9). Conversely, a large single-centre retrospective study of 1050 patients who underwent MDCT for TAVI workup described no difference in survival in TAVI patients with versus without clinically relevant IF at 30 days or 1 year(7). We similarly found no survival difference in our overall cohort however, three out of four patients with IF-ICS who did not undergo TAVI died. A key difference to explain the disparate findings is the inconsistent risk stratification of IF where clearly not all IF are equivalent in impacting prognosis. Thus such findings, their likelihood of malignancy and urgency of correlation or follow-up should be communicated to the Heart Team. A subsequent holistic decision can be made regarding appropriateness and timing of TAVI or other treatments.

Although previous studies have primarily focused on the impact of IF on survival, we aimed to also evaluate the outcome of reported suspicious IF during follow-up. In six patients with IF-ICS, all were subsequently discovered to have malignant lung cancer. While certainly other primary organ tumours cannot be overlooked, clinicians should maintain a high index of suspicion regarding lung pathology, particularly because dyspnoea and exercise intolerance are complaints in both lung cancer and severe AS. Such findings alter treatment decisions as lung cancer portends a poor prognosis in an elderly age group and TAVI may not be a feasible option in those with a life expectancy of less than 12 months. Despite this, three patients with lung cancer eventually underwent TAVI, with one patient proceeding after successful remission post lung cancer treatment. Nevertheless, the presence of large pulmonary nodules (5 to $8 \mathrm{~mm}$ or more) still has a relatively low malignant potential with only 2 out of 87 patients diagnosed with lung cancer during a median follow-up of 1.25 years in another single-centre retrospective study(8). It could be argued that such a finding should not necessarily delay treatment for severe 
AS as it may not impact survival(16). Cohesive judgment from both the multidisciplinary Heart Team and Thoracic team is vital to direct appropriate treatment.

In patients with IF-NICS, about $40 \%$ of potentially malignant findings were further investigated in this study and all found to be benign. While such findings may be detailed in the MDCT report, explicit recommendations regarding correlation, further investigation or follow-up may not be outlined in the reporting conclusion. Also, findings of unclear significance may not be verbally communicated to the treating team due to the likely benign natural history. This is not unusual with data on incidental pulmonary nodules noted on CT pulmonary angiographic studies demonstrating follow-up of nodules was generally poor $(<30 \%)$ and reduced to $0 \%$ when nodules were only reported in the findings section alone(17). Importantly, the addition of the Fleischner Society guidelines for incidental pulmonary nodules on chest CT reports significantly increased the likelihood of patients receiving the recommended follow-up care(18). Evidently, standardised templates for reporting MDCT in TAVI workup, while potentially cumbersome, provides clinicians with a clear understanding of relevant follow-up and improved holistic care of patients. The perceived total cost of further investigations accrued from MDCT findings has been reported as relatively low and should not be prohibitive(19). However, the lack of followup regarding IF may also represent individual discussion with patients regarding such findings that may have led to a collaborative decision not to investigate further. While this is not captured in our data, it is not unreasonable in IF which may have malignant potential but are unlikely to drastically affect prognosis in the elderly. It therefore should not necessarily delay the decision to perform TAVI provided the life expectancy of the patient is greater than 12 months.

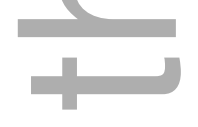

\section{Clinical application}

Requests for MDCT as part of TAVI assessment will increase as TAVI uptake expands into potentially intermediate and low-risk AS patients. In Australia, TAVI numbers are projected to increase up to 4-10 times, particularly if low-risk populations are offered TAVI in the future (20). Members of the Heart Team may not be aware of IF on MDCT unless reasonably communicated or recognise the clinical significance of such findings. This is particularly challenging given the 
sheer frequency of IF that emerge from MDCT given the large body regions imaged.

2 Standardised reporting templates for MDCT are valuable not only for consistent vascular assessment for TAVI but potentially for clear specification of incidental findings, their clinical significance, and relevant follow-up. However, the presence of IF must be correlated with the 5 patient's clinical history and examination which may not be accessible to the reporting radiologist. Thus a multidisciplinary approach with clear communication is crucial to determining and reporting the clinical significance of IF on MDCT for TAVI assessment. Furthermore, while renal, adrenal and thyroid pathologies were common in this study, particular suspicion should be raised for lung pathologies in view of their frequency, malignant potential and overlapping clinical presentation with severe AS(21). Finally, it is currently unclear whether potentially malignant findings on MDCT impact survival. While clearly each IF should be considered on an individual basis, the decision to proceed with TAVI should not necessarily be delayed if the incidentaloma is unlikely to significantly alter prognosis and can be investigated at a later stage.

\section{Limitations}

We acknowledge several limitations to this study. First, these data arise from a retrospective review of MDCT reports amongst potential TAVI candidates from a prospectively-maintained registry. There have been no prospective studies in this area thus far and this could influence the frequency of IF noted. Second, this study involved a single centre and it is unclear whether the rate of IF and their follow-up can be extrapolated to other institutions. Third, our median followup was relatively limited and thus conclusions regarding survival must be interpreted with caution, especially since IF may only affect intermediate to long term survival. Fourth, the MDCT was reported by radiologists at our centre and their threshold for reporting IF will differ. These data reflect real-world experience and we opted not to further review MDCT reports to potentially detect more IF a priori. Finally, it is possible that patients may have had their IF investigated at an external institution or imaging centre. While these were not accessible in these data, we reviewed medical record notes to determine if any further external correspondence including imaging conducted elsewhere were performed. 


\section{CONCLUSION}

3 Incidental findings on MDCT are common with $22 \%$ of patients having an IF-NICS and $2 \%$ of patients having IF-ICS. Common pathologies involve the lung and kidney, with all malignant findings related to the lung. Most patients (60\%) with IF-NICS did not undergo further investigation. Standardised reporting of MDCT may assist with consistent reporting of IF and recommended follow-up strategy which will in turn influence the decision to proceed with TAVI and its appropriate timing.

\section{REFERENCES}

1. Nelson AJ, Montarello NJ, Cosgrove CS, Roberts-Thomson RL, Delacroix S, Chokka RG, et al. Transcatheter aortic valve implantation: a new standard of care. The Medical journal of Australia. 2018;209(3):136-41.

2. Nishimura RA, Otto CM, Bonow RO, Carabello BA, Erwin JP, 3rd, Fleisher LA, et al. 2017 AHA/ACC Focused Update of the 2014 AHA/ACC Guideline for the Management of Patients With Valvular Heart Disease: A Report of the American College of Cardiology/American Heart Association Task Force on Clinical Practice Guidelines. Circulation. 2017;135(25):e1159-e95.

18 3. Bloomfield GS, Gillam LD, Hahn RT, Kapadia S, Leipsic J, Lerakis S, et al. A practical guide to multimodality imaging of transcatheter aortic valve replacement. JACC Cardiovascular imaging. 2012;5(4):441-55.

4. Orme NM, Wright TC, Harmon GE, Nkomo VT, Williamson EE, Sorajja P, et al. Imaging Pandora's Box: incidental findings in elderly patients evaluated for transcatheter aortic valve replacement. Mayo Clinic proceedings. 2014;89(6):747-53. "Incidental findings" during TAVI work-up: more than just an inconvenience. EuroIntervention : journal of EuroPCR in collaboration with the Working Group on Interventional Cardiology of

27 the European Society of Cardiology. 2015;11(4):465-9.

28 6. Stachon P, Kaier K, Milde S, Pache G, Sorg S, Siepe M, et al. Two-year survival of patients screened for transcatheter aortic valve replacement with potentially malignant incidental 
1 findings in initial body computed tomography. European heart journal cardiovascular Imaging.

2 2015;16(7):731-7.

3 7. Trenkwalder T, Lahmann AL, Nowicka M, Pellegrini C, Rheude T, Mayr NP, et al.

4 Incidental findings in multislice computed tomography prior to transcatheter aortic valve

5 implantation: frequency, clinical relevance and outcome. The international journal of cardiovascular imaging. 2018;34(6):985-92.

7 8. Schmidt LH, Vietmeier B, Kaleschke G, Schulke C, Gorlich D, Schliemann C, et al.

8 Thoracic Malignancies and Pulmonary Nodules in Patients under Evaluation for Transcatheter Aortic Valve Implantation (TAVI): Incidence, Follow Up and Possible Impact on Treatment Decision. PloS one. 2016;11(5):e0155398.

11 9. van Kesteren F, Wiegerinck EMA, van Mourik MS, Vis MM, Koch KT, Piek JJ, et al.

12 Impact of Potentially Malignant Incidental Findings by Computed Tomographic Angiography on Long-Term Survival After Transcatheter Aortic Valve Implantation. The American journal of cardiology. 2017;120(6):994-1001.

10. Bhambhvani P. The good, bad, and ugly of incidental findings on cardiovascularcomputed tomography. Journal of Nuclear Cardiology. 2016;23(6):1275-9.

\section{Apfaltrer P, Schymik G, Reimer P, Schroefel H, Sueselbeck T, Henzler T, et al.} Aortoiliac CT Angiography for Planning Transcutaneous Aortic Valve Implantation: Aortic Root Anatomy and Frequency of Clinically Significant Incidental Findings. American Journal of Roentgenology. 2012;198(4):939-45.

12. Fathala A, Bin Saeedan M, Zulfiqar A, Al Sergani H. Non-Cardiovascular Computed Tomography Incidental Findings in Patients Who Underwent Transaortic Valve Implantation Procedure. Cardiol Res. 2017;8(1):13-9.

13. Gufler H, Schulze CG, Wagner S. Incidental findings in computed tomographic angiography for planning percutaneous aortic valve replacement: advanced age, increased cancer prevalence? Acta Radiologica. 2014;55(4):420-6.

14. Hussien AF, Jeudy J, Kligerman SJ, White CS. Thoracic Incidental Findings in Preoperative Computed Tomography Evaluation for Transcatheter Aortic Valve Implantation 29 (TAVI). Journal of thoracic imaging. 2016;31(3):183-8.

30 15. Marcovici PA, Taylor GA. Structured Radiology Reports Are More Complete and More 31 Effective Than Unstructured Reports. American Journal of Roentgenology. 2014;203(6):1265-71. 
16. Markowiak T, Holzamer A, Hilker M, Pregler B, Debl K, Hofmann HS, et al. Incidental

2 thoracic findings in computed tomography scans before transcatheter aortic valve implantation.

3 Interact Cardiovasc Thorac Surg. 2018.

4 17. Blagev DP, Lloyd JF, Conner K, Dickerson J, Adams D, Stevens SM, et al. Follow-up of

5 Incidental Pulmonary Nodules and the Radiology Report. J Am Coll Radiol. 2016;13(2

6 Suppl):R18-24.

7 18. McDonald JS, Koo CW, White D, Hartman TE, Bender CE, Sykes AG. Addition of the

8 Fleischner Society Guidelines to Chest CT Examination Interpretive Reports Improves

9 Adherence to Recommended Follow-up Care for Incidental Pulmonary Nodules. Acad Radiol.

$10 \quad 2017 ; 24(3): 337-44$.

11 19. Lindsay AC, Sriharan M, Lazoura O, Sau A, Roughton M, Jabbour RJ, et al. Clinical and 12 economic consequences of non-cardiac incidental findings detected on cardiovascular computed 13 tomography performed prior to transcatheter aortic valve implantation (TAVI). The international 14 journal of cardiovascular imaging. 2015;31(7):1435-46.

15 20. Adams HSL, Ashokkumar S, Newcomb A, MacIsaac AI, Whitbourn RJ, Palmer S. A

16 Contemporary Review of Severe Aortic Stenosis. Internal medicine journal. 2018;0(ja).

17 21. Staab W, Bergau L, Lotz J, Sohns C. Prevalence of noncardiac findings in computed tomography angiography before transcatheter aortic valve replacement. Journal of cardiovascular computed tomography. 2014;8(3):222-9.

\section{FIGURE LEGEND} clinical significance. 
1 Primary bronchogenic carcinoma identified in patient no. 7 in (A) coronal view and (B) axial

2 view. At the left hilum, there is a soft tissue mass which compresses the left upper lobe

3 pulmonary artery and narrows the left upper lobe bronchus. The mass measures approximately

$430 \times 28 \times 30 \mathrm{~mm}$ and invades the adjacent mediastinal fat.

5

6 Figure 3. Survival from MDCT

7 (A) Overall survival in entire cohort from MDCT date. (B) Overall survival in TAVI patients

8 from MDCT date.

9 IF, Incidental finding; IF-ICS, Incidental finding of immediate clinical significance; IF-NICS,

10 Incidental finding of non-immediate clinical significance; IF-NoCS, Incidental finding of no

11 relevant clinical significance; MDCT, Multi-detector computed tomography; TAVI,

12 Transcatheter aortic valve implantation

13 Table 1. Baseline characteristics

\begin{tabular}{lcccc}
\hline & $\begin{array}{c}\text { Total, } \\
\mathbf{n = 2 6 5}\end{array}$ & $\begin{array}{c}\text { TAVI, } \\
\mathbf{n = 1 7 1}\end{array}$ & $\begin{array}{c}\text { No TAVI, } \\
\mathbf{n = 9 4}\end{array}$ & $\begin{array}{c}\text { p-value for } \\
\text { difference }\end{array}$ \\
\hline Age, mean years \pm SD & $83 \pm 6$ & $83 \pm 5$ & $82 \pm 6$ & 0.90 \\
Male (\%) & $137(52)$ & $82(48)$ & $55(59)$ & 0.12 \\
NYHA class (\%) & & & \\
I & $16(6)$ & $5(3)$ & $11(13)$ & $\mathbf{0 . 0 1}$ \\
II & $164(62)$ & $106(62)$ & $58(62)$ & \\
III & $66(25)$ & $46(27)$ & $20(21)$ & \\
IV & $14(5)$ & $11(6)$ & $3(3)$ & \\
Not recorded & $5(2)$ & & & \\
Comorbidities & & & $37(39)$ & $\mathbf{0 . 0 4}$ \\
Diabetes mellitus $(\%)$ & $174(66)$ & $120(70)$ & $54(57)$ & 0.09 \\
Hypercholesterolemia (\%) & $223(84)$ & $148(87)$ & $75(80)$ & 0.46 \\
Hypertension (\%) & $131(49)$ & $100(59)$ & $31(33)$ & $<\mathbf{0 . 0 0 1}$ \\
IHD (\%) & $76(29)$ & $48(28)$ & $28(30)$ & 0.67 \\
CKD (\%) & & & \\
\hline
\end{tabular}

This article is protected by copyright. All rights reserved 


\begin{tabular}{lcccc}
\hline COPD (\%) & $33(12)$ & $20(12)$ & $13(14)$ & 0.56 \\
History of smoking (\%) & $102(38)$ & $67(39)$ & $35(37)$ & 0.93 \\
Previous CVA (\%) & $28(11)$ & $17(11)$ & $11(13)$ & 0.68 \\
Previous PCI (\%) & $56(21)$ & $44(26)$ & $12(13)$ & $\mathbf{0 . 0 3}$ \\
Previous CABG $(\%)$ & $55(21)$ & $42(25)$ & $13(14)$ & 0.08
\end{tabular}

1 CABG, Coronary artery bypass grafts; CKD, Chronic kidney disease; COPD, Chronic obstructive

2 pulmonary disease; CVA; Cerebrova scular event; IHD, Ischaemic heart disease; NYHA, New York Heart

3 Association; PCI, Percutaneous coronary intervention; TAVI, Transcatheter a ortic valve implantation

4 Table 2. Incidental findings on MDCT.

5

\begin{tabular}{lccc}
\hline & $\begin{array}{c}\text { Total, } \\
\mathbf{n = 2 6 5}\end{array}$ & $\begin{array}{c}\text { TAVI, } \\
\mathbf{n = 1 7 1}\end{array}$ & $\begin{array}{c}\text { No TAVI, } \\
\mathbf{n = 9 4}\end{array}$ \\
\hline Lung nodule (\%) & $48(18)$ & $27(16)$ & $21(22)$ \\
Single & 33 & 17 & 16 \\
Multiple & 15 & 10 & 5 \\
Largest size, mean (range) in mm & $11(2-38)$ & $(3-30)$ & $(2-38)$ \\
Size not specified & 14 & 4 & 10 \\
Pleural effusion & $25(9)$ & $9(5)$ & $16(17)$ \\
Mediastinal/hilar lymphadenopathy (\%) & $27(10)$ & $12(7)$ & $15(16)$ \\
Liver nodule/cyst (\%) & $21(8)$ & $15(9)$ & $6(6)$ \\
Single & 8 & 5 & 3 \\
Multiple & 13 & 10 & 3 \\
Largest size, mean (range) in mm & $12(2-28)$ & $(2-10)$ & $(2-28)$ \\
Size not specified & 14 & 10 & 4 \\
Renal lesion(\%) & $67(25)$ & $43(25)$ & $24(26)$ \\
Unilateral & 53 & 33 & 20 \\
Bilateral & $10(3)$ & $7(4)$ & $3(3)$ \\
Simple/uncomplicated & $58(3-90)$ & $(7-90)$ & $(3-90)$ \\
Complex & 46 & 28 & 18 \\
Largest size, mean (range) in mm & 59 & 40 & 19 \\
Size not specified & 3 & 2 & 1 \\
Pancreatic lesion (\%) & & & 4 \\
\hline
\end{tabular}

This article is protected by copyright. All rights reserved 


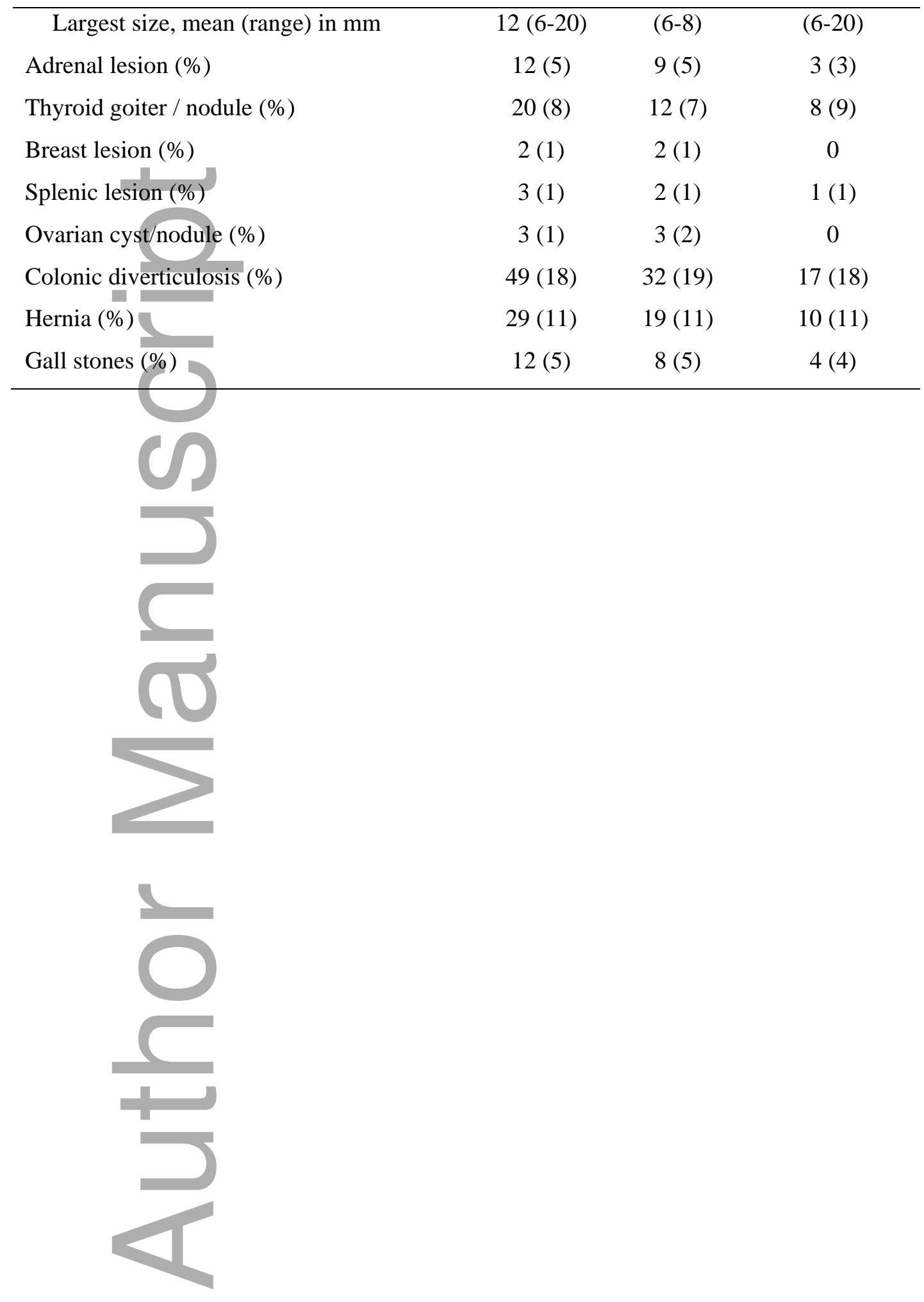

This article is protected by copyright. All rights reserved 
1 Table 3. Patients with suspected or confirmed malignant cancer diagnosis.

\begin{tabular}{|c|c|c|c|c|c|c|c|c|c|}
\hline $\begin{array}{c}\text { Patient } \\
\text { no. }\end{array}$ & Age & Sex & $\begin{array}{l}\text { Related } \\
\text { organ }\end{array}$ & $\begin{array}{l}\text { Largest } \\
\text { diameter }\end{array}$ & $\begin{array}{c}\text { Primary cancer } \\
\text { diagnosis }\end{array}$ & Histopathology & TAVI & $\begin{array}{c}\text { Follow-up post } \\
\text { MDCT, days }\end{array}$ & Outcome \\
\hline 1 & 81 & $\mathrm{M}$ & Lung & NS & Stage IA lung & Suspected NSCLC & Yes & 511 & Alive \\
\hline 2 & & M & Lung & $17 \mathrm{~mm}$ & Stage IA lung & $\begin{array}{l}\text { Squamous cell } \\
\text { carcinoma }\end{array}$ & No & 431 & Dead \\
\hline 3 & & $\mathrm{~F}$ & Lung & $27 \mathrm{~mm}$ & Stage IV lung & NSCLC & No & 220 & Dead \\
\hline 4 & & M & Lung & NS & $\begin{array}{l}\text { Stage IV } \\
\text { colorectal } \\
\text { primary }\end{array}$ & $\begin{array}{c}\text { Sigmoid } \\
\text { adenocarcinoma }\end{array}$ & No & 373 & Dead \\
\hline 5 & & M & Lung & $38 \mathrm{~mm}$ & Stage IIA lung & Adenocarcinoma & No & 22 & Alive \\
\hline 6 & & M & Lung & 27 & $\begin{array}{l}\text { Stage IA lung } \\
\text { primary }\end{array}$ & $\begin{array}{c}\text { Pleomorphic } \\
\text { carcinoma }\end{array}$ & Yes & 168 & Alive \\
\hline 7 & 80 & M & Lung & 30 & Stage IIIA lung & NSCLC & Yes & 604 & Alive \\
\hline
\end{tabular}

This article is protected by copyright. All rights reserved 
1 Table 4. Studies of suspicious incidental findings on MDCT and association

2 with mortality.

\begin{tabular}{|c|c|c|c|c|c|}
\hline Author (year) & $\begin{array}{c}\text { No. of } \\
\text { patients }\end{array}$ & $\begin{array}{l}\text { Age, } \\
\text { years }\end{array}$ & $\begin{array}{c}\text { Incidence of } \\
\text { suspicious } \\
\text { IF }\end{array}$ & $\begin{array}{l}\text { Follow-up, } \\
\text { months }\end{array}$ & $\begin{array}{c}\text { Association between suspicious } \\
\text { IF and mortality }\end{array}$ \\
\hline Orme et al. (2014) & 424 & $82 \pm 8$ & $67 \%$ & 9.5 & $\begin{array}{c}\text { Adjusted HR 1.45, } \\
95 \% \text { CI } 1.19-1.76, \mathrm{p}<0.01\end{array}$ \\
\hline Lindsay et al.(2015) & 279 & 79 & $19 \%$ & 24 & No association $(\mathrm{p}=0.56)$ \\
\hline Showkathali et al. (2015) & 295 & $83 \pm 7$ & $30 \%$ & 21 & $\begin{array}{c}\text { Adjusted HR 1.5, } \\
95 \% \text { CI 1-2.2, } \mathrm{p}=0.04\end{array}$ \\
\hline Stachon et al. (2015) & 414 & $80 \pm 9$ & $19 \%$ & 24 & No association $(\mathrm{p}=0.82)$ \\
\hline Kesteren et al. (2018) & 553 & 82 & $25 \%$ & 60 & $\begin{array}{c}\text { Adjusted HR 1.84, } \\
95 \% \text { CI 1.06-3.20, } \mathrm{p}=0.03\end{array}$ \\
\hline Patel et al. (2018) & 138 & 80 & $57 \%$ & 18 & No association $(\mathrm{p}=0.48)$ \\
\hline Trenkwalder et al. (2018) & 1050 & $80 \pm 7$ & $25 \%$ & 20 & No association $(\mathrm{p}=0.79)$ \\
\hline
\end{tabular}




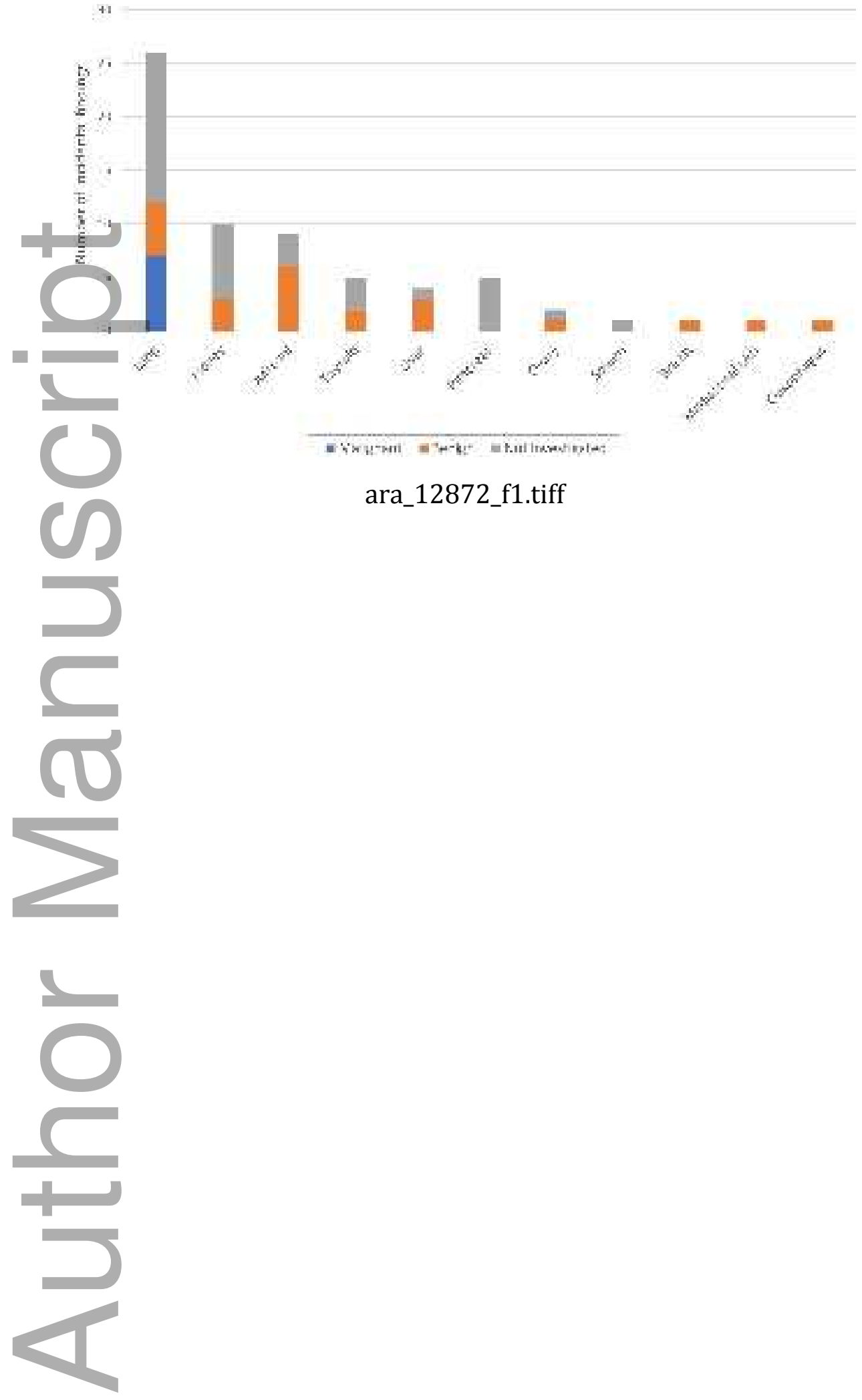

This article is protected by copyright. All rights reserved 


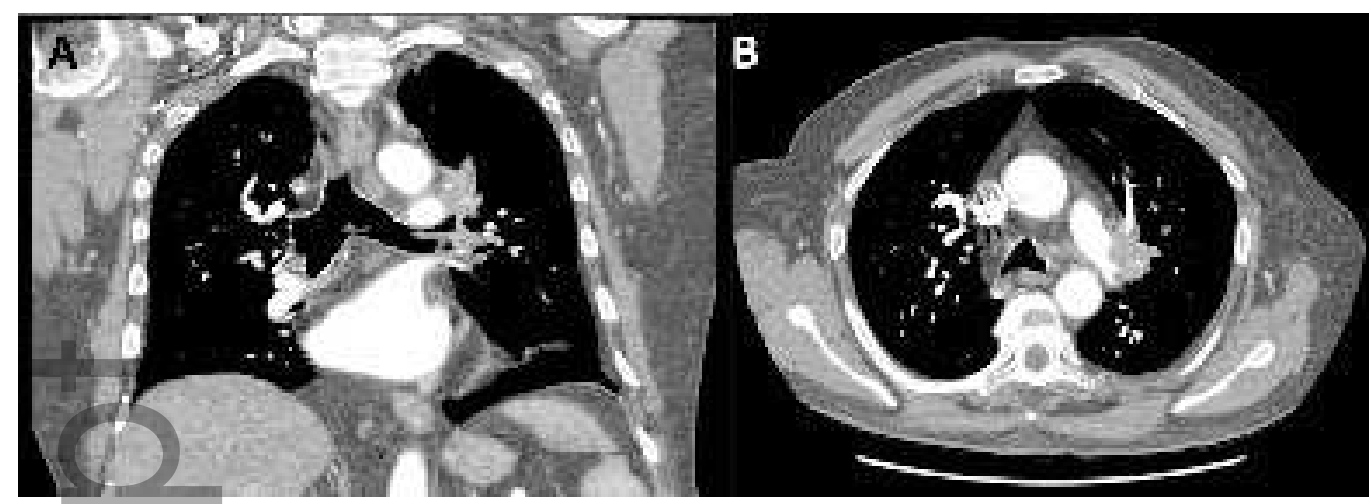

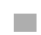

ara_12872_f2.tiff
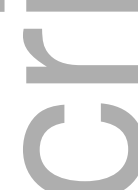

$\sqrt{0}$
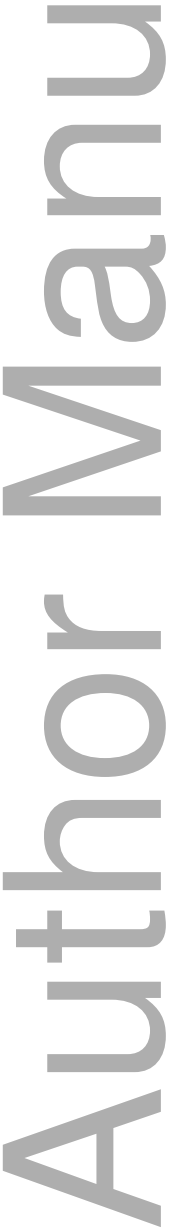

This article is protected by copyright. All rights reserved 


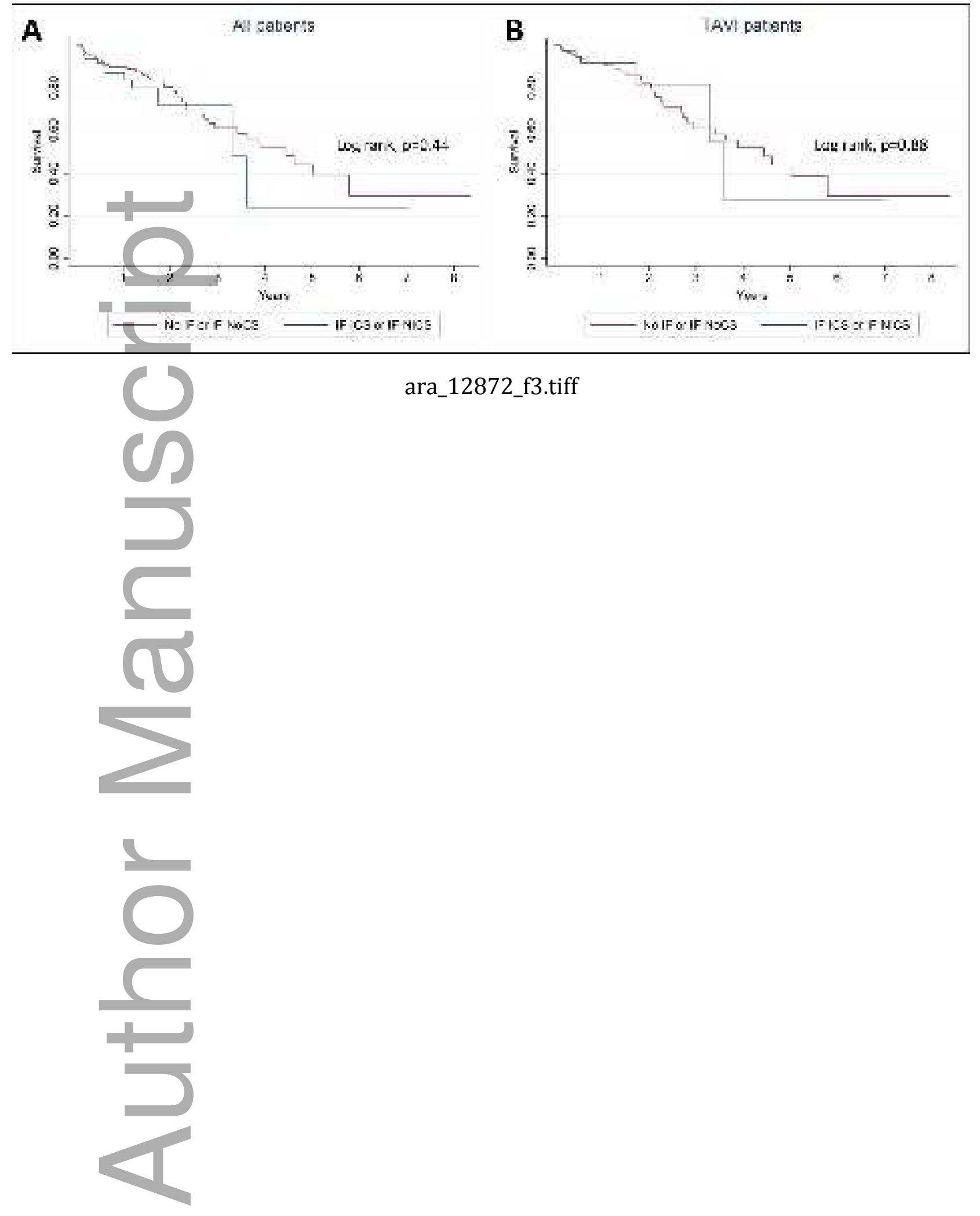

This article is protected by copyright. All rights reserved 


\section{University Library}

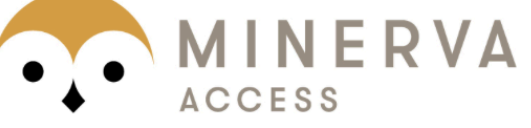

A gateway to Melbourne's research publications

Minerva Access is the Institutional Repository of The University of Melbourne

Author/s:

Ha, FJ;Tham, JLM;Paleri, S;Wright, C;Yap, KK;Adams, HSL;Whitbourn, RJ;Palmer, SC

Title:

Outcomes of incidental findings on multi-detector computed tomography for transcatheter aortic valve implantation assessment: A single-centre study and review of the literature

Date:

2019-08-01

Citation:

Ha, F. J., Tham, J. L. M., Paleri, S., Wright, C., Yap, K. K., Adams, H. S. L., Whitbourn, R. J. \& Palmer, S. C. (2019). Outcomes of incidental findings on multi-detector computed tomography for transcatheter aortic valve implantation assessment: A single-centre study and review of the literature. JOURNAL OF MEDICAL IMAGING AND RADIATION ONCOLOGY, 63 (4), pp.446-453. https://doi.org/10.1111/1754-9485.12872.

Persistent Link:

http://hdl.handle.net/11343/285586 